\title{
Effect of heat Transfer Through Arbitrary Shaped fins using Computational Fluid Dynamics
}

\author{
K.Balashowry, T.Saikrishna, K.Sri Hari Charan Reddy, Mandhula Kalyan
}

\begin{abstract}
An automobile engine produces a lot of heat and is subjected to thermal stresses. These high temperatures and thermal stresses generated might cause distortions in the engine components and also reduces the volumetric efficiency of the engine. It is important to remove this heat generated to ensure the ideal functionality of the engine. In order to dissipate this heat out of the engine through convection, extended surfaces(fins) are used as a medium, projected to the engine walls. In the present analysis, arbitrary shaped fins of same surface area are designed and heat transfer analysis is performed. Using the ANSYS Fluent software the analysis is done. The main intent of our study is to increase the heat transfer rate using the arbitrary shaped fins. The results obtained are compared with the regular shaped solid fins. Results show there's a significant increase in heat transfer through the arbitrary shaped fins. The fin with elliptical hole has greater heat transfer rate than other models of fins used in the analysis.

Keywords: CFD, Convection, Fins, Notches.
\end{abstract}

\section{INTRODUCTION}

Heat transfer is a phenomenon of transfer of energy on account of temperature difference. This phenomenon plays an important role in cooling the engines in automobiles.

The two majorly used cooling systems are

(i) Cooling system using air and

(ii) Cooling system using water

Cooling system using air are preferred in small vehicles because of its advantages like,1) It is cheaper to manufacture as its design is uncomplicated. with water, as it requires no water jackets, radiator,

Pump for circulating and the cooling water weight.

The three ways in which heat is transferred are

1. Conduction 2.Convection and 3.Radiation. In the present analysis the convective heat transfer is taken into account.

Convection $=\mathrm{h} * \mathrm{~A} *(\mathrm{Ts}-\mathrm{T} \infty)$

Where, $\mathrm{h}=$ convective heat transfer coefficient

Ts $=$ Temperature of hot surface

$\mathrm{T} \infty=$ Surrounding temperature

$\mathrm{A}=$ area of contact or exposure

Revised Manuscript Received on September 25, 2020.

* Correspondence Author

K.Balashowry*, Professor, Department of Mechanical Engineering, VNR Vignana Jyothi Institute of Engineering and Technology, Hyderabad, India. Email: balashowry_k@vnrvjiet.in

T.Saikrishna, Department of Mechanical Engineering, VNR Vignana Jyothi Institute of Engineering and Technology, Hyderabad, India. Email: saikrishna12377@gmail.com

K.Sri Hari Charan Reddy, Department of Mechanical Engineering, VNR Vignana Jyothi Institute of Engineering and Technology, Hyderabad, India. Email: saicharan662000@gmail.com

Mandhula Kalyan, Department of Mechanical Engineering, VNR Email: kalyankali3992@gmail.com

(c) The Authors. Published by Blue Eyes Intelligence Engineering and Sciences Publication (BEIESP). This is an open access article under the CC BY-NC-ND license (http://creativecommons.org/licenses/by-nc-nd/4.0/)
2)It is lighter in weight than engines using cooling system Vignana Jyothi Institute of Engineering and Technology, Hyderabad, India.

From the above expression it is clear that the convective heat transfer rate can be increased by increasing

-> Temperature difference (Ts-To)

$->$ Convection heat transfer coefficient

$->$ Area of exposure

To increase $h$, it is required to install a pump or replace the existing one with a larger one. So, to avoid this we prefer altering the area of exposure. To increase the area without much increase in the material, fins are used. Fins provide the area to be exposed to the surrounding and thus increase the heat transfer rate.

\section{LITERATURE REVIEW}

AkshendraSoniet.al studied the performance of Plate-fin, Pin-fin and Elliptical Fins heat Sinks in Closed Enclosure under Natural Convection thermally. In this paper the author determined thermal performances of plate-fin, pin-fin and elliptical heat sinks with base plate which is vertical. The author investigated the steady state heat transfer for natural convection and thermal performance comparison between rectangular finned heat sinks and pin fin heat sink from vertically-oriented base plate. On the elliptical fin, a methodical numerical study is done.A3-D numerical model for the study of different fin geometries effects is made using SOLIDWORKS and ANSYS. From his study the author writes, the changes from the geometry of finto base plate fins with vertical orientation enhances the thermal performance of fins and decrease the weight of the fin arrays, which reduces the cost of manufacturing. The results show the important structural parameter impacting the heat transfer from pin fin arrays is the ratio of the diameter of the fin to the center to center distance [1]. K.Sathishkumaret.al, worked on Computational Analysis of Heat Transfer through Fins with notches of different shapes, in this paper the author selected three different types of notches, 1.Finshaving Holes.2.Fins having Rectangular Notches.3.Fins having V - Shaped Notches. The material chosen here is aluminum because aluminum has good electrical and thermal conductivity, possess 59\% the thermal and electrical conductivity of copper with only $39 \%$ of the density of copper. The author also performed theoretical calculations to finer the heat transfer rate. The theoretical and software results show the rectangular notched fin have greater rate of heat transfer than that of the fins having no holes, fins having holes and V shaped fins[2]. N.Nagarani et.al, experimentally analyzed the Heat Transfer on Annular and Elliptical Fins. In this paper the author performed experimental analysis of fins made of aluminum. The experiment is conducted by free convection. The air's temperature that is entering the test specimen is measured as

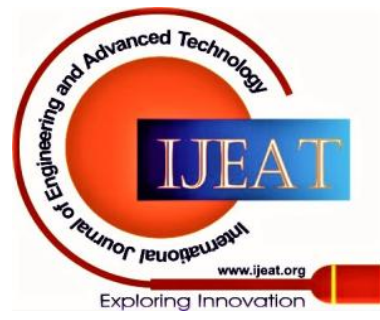


the ambient temperature and the temperature of the test fins are measured with the help of thermocouples of $\mathrm{K}$ type. Using another thermocouple, the inlet and outlet temperatures of the circular tube are measured. Results shows the efficiency of elliptical fin is higher than circular fin[3].

Mayank et.al heat transfer analysis and optimization of fins by variation in geometry, in the paper, structural fins models are made to predict the transient thermal behavior. The authors used CREO parametric 2.0 to create geometries such as rectangular, circular, and triangular and fins with extension. The analysis is done using ANSYS 14.5. Aluminum Alloy 6061 is used as it has higher thermal conductivity of about $160-170 \mathrm{~W} / \mathrm{m}-{ }^{\circ} \mathrm{C}$. The authors studied the heat transfer rate by varying the geometrical parameters such as cross sectional area, parameter, length, thicknessetc. The analysis results show the Aluminum alloy 6061 triangular fin has better rate of heat transfer compared to others[4].

Rafeek Shaikhet.al conducted a review on Experimental study of heat transfer from Plate Fin in Mixed Convection Mode (Square, Elliptical and Circular Fin), in this review paper the authors explained about the theory of mixed convection. The authors concluded that the mixed convection heat transfer changes as fin shape changes, and the heat transfer is higher in mixed convection mode[5].

N.A.Nawale et.al conducted,experiment on Heat Transfer through Fins Having Different Notches, in this paper the authors performed experimental analysis of the rectangular fins with horizontal arrays for natural convection. From the experimental analysis it has been observed that distribution of temperature for the fin with notch is more regular than the fins having no notch. Results haveshown the heat transfer coefficient is highest for the set of fins with triangular notch [6].

A.-R.A.Khaled et.al had investigated, Heat Transfer Enhancement through Permeable Fins, in this paper, the heat transfer through rectangular permeable fins is modeled and analyzed theoretically.From the study the author wrote the permeable fins may have superiority in transferring heat over ordinary solid fins, especially at large suction velocity values and moderate holes-to-fin surface area ratios [7].

V. Karthikeyan et.al worked on the Design and Analysis of Natural Convective Heat Transfer Coefficient Comparison between Rectangular Fin Arrays with Perforated and Fin Arrays with Extension, in this paper the authors studied the heat transfer rate of Rectangular fin arrays and analyzed by design with perforated and with extension. The author concluded that the fin arrays having rectangular extensions provide about $13 \%$ to $21 \%$ higher enhancement of transfer of heat as compare to the fins of other types[8].

Sunil S, et.al studied the Heat Transfer Enhancement and Thermal Performance of Extended Fins, in this paper the authors performed thermal analysis for various perforated fin extensions with varied diameter. Results shows the heat transfer through rectangular fin with $20 \mathrm{~mm}$ perforation and $3 \mathrm{~mm}$ cutout provide $33.79 \%$ of heat transfer enhancement compared to other models and is higher than other type of fins[9].

Sanjay Kumar Sharmaet.al done work on maximizing the Heat Transfer through Fins Using computational fluid dynamics, in this paper the author studied using Ansys fluent to find the optimum pin shape based on minimum pressure drop. The results show that the drop shaped pin finshave improved results [10] .on the basis of heat transfer and pressure drop by comparing other fins.

\section{METHODOLOGY}

In this paper, the methodology followed is given by the following flow chart. Initially a set of papers related to the problem is collected and studied. Then using the SOLID WORKS, the shapes of the fins are designed. Each fin is provided with same surface area varying its length and keeping width and thickness constant. Then using the ANSYS software the analysis of the model is done. The results obtained from the analysis are studied.

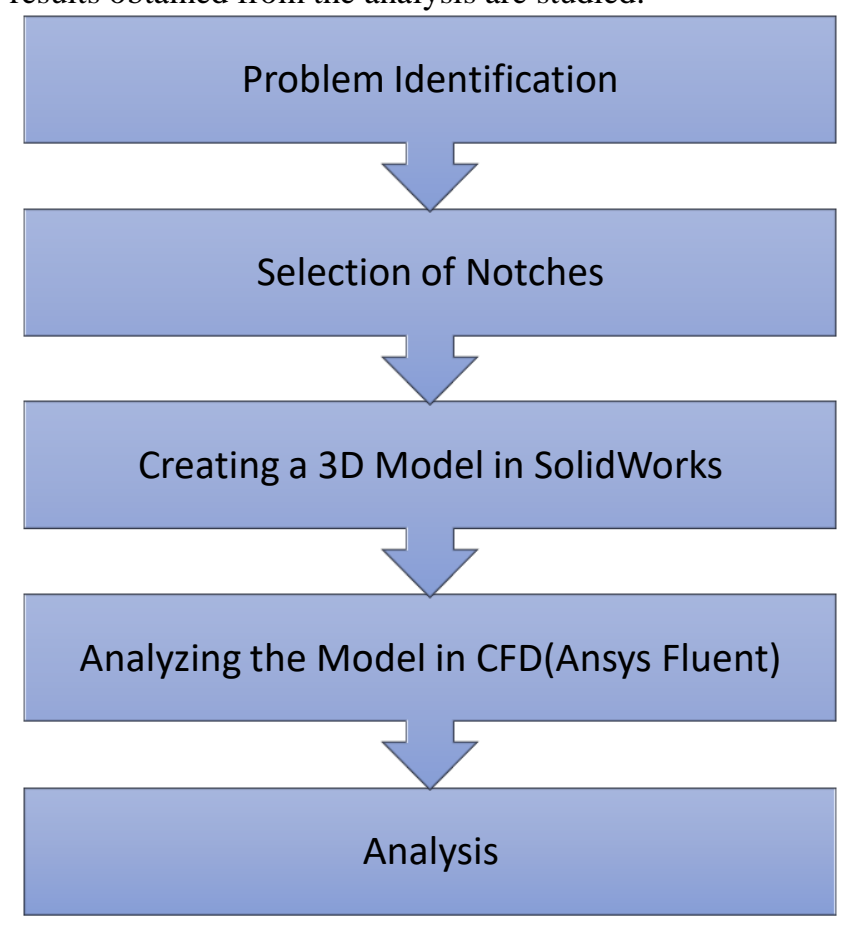

IV.

DESIGN OF MODELS

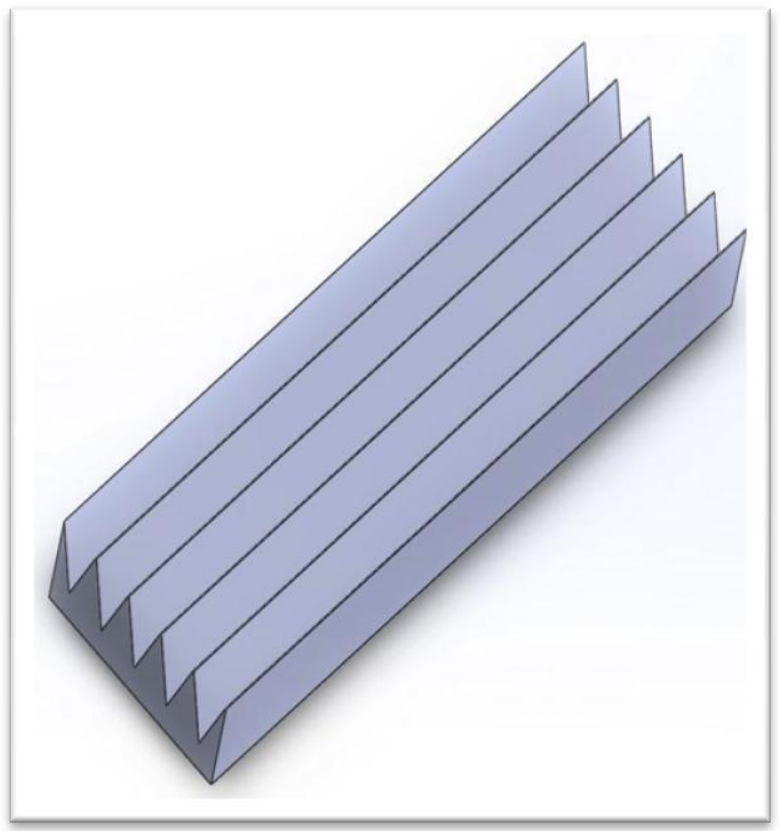

Fig.1 Triangular notch

Published By:

Blue Eyes Intelligence Engineering and Sciences Publication

(C) Copyright: All rights reserved.

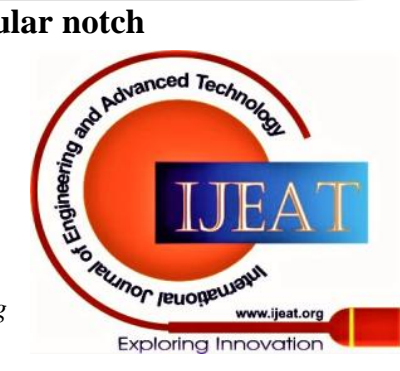




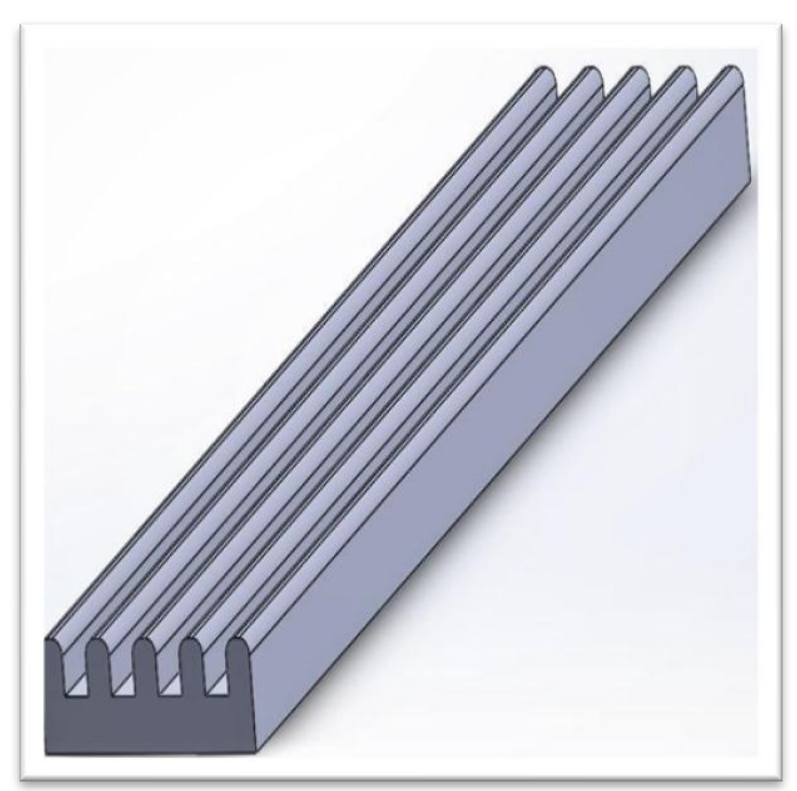

Fig.2 Squared notch

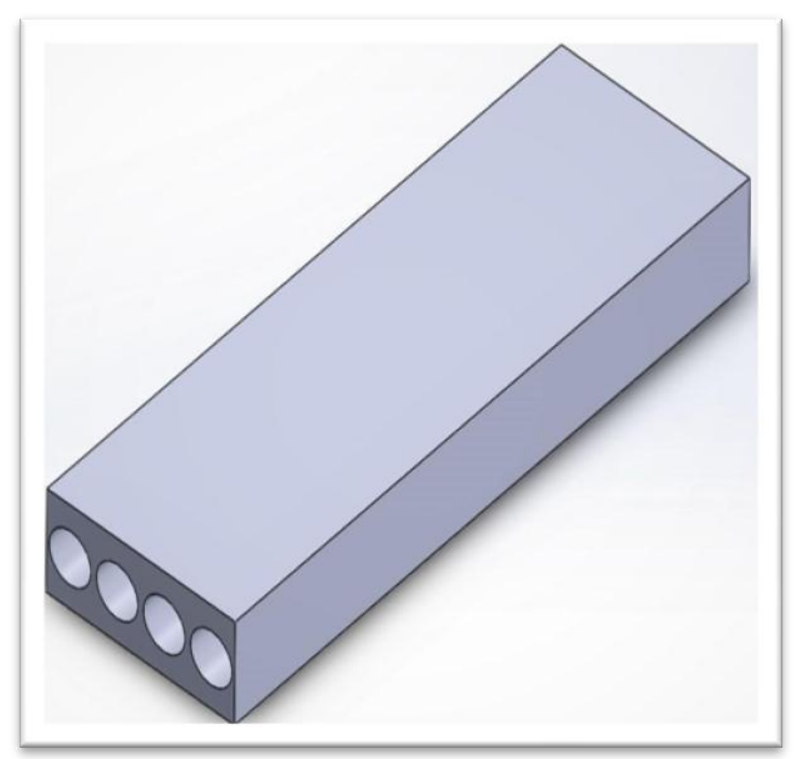

Fig.3 Elliptical hole

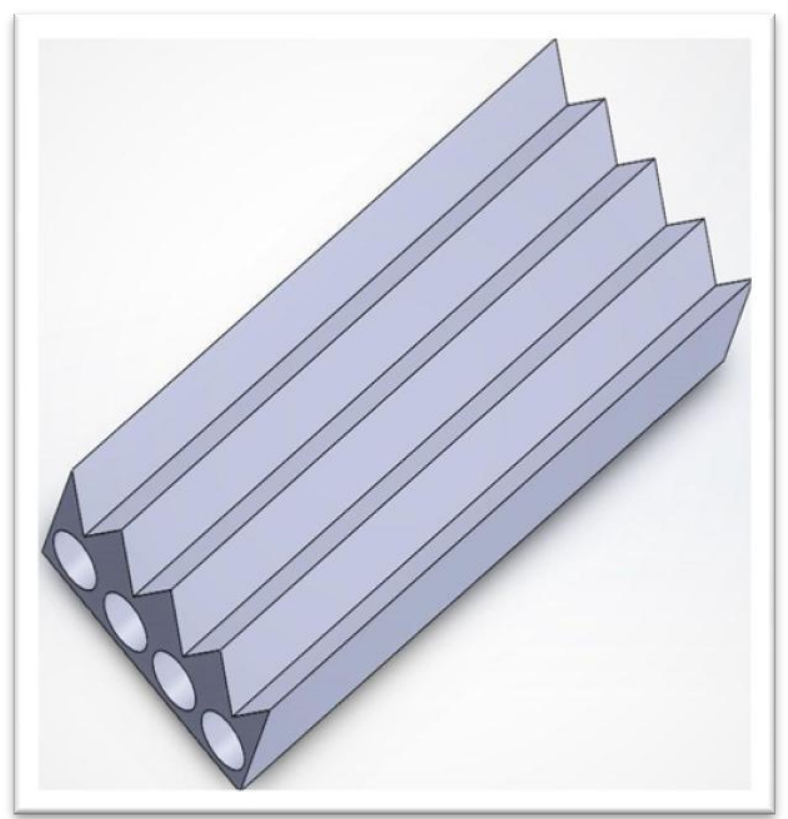

Fig.4 Triangular not ch with elliptical hole

\section{DESIGN AND CFD ANALYSIS}

The fins are designed using solid works software and extruded as three-dimensional models in the same solid works. These models are imported in the ANSYS work bench for meshing. Once meshing was completed, the inlet boundary conditions were assigned so as to initiate the simulation process. After assigning the boundary conditions the problem was exported to solver in Ansys Fluent wherein the simulation process takes place.

Fins are critical to solve analytically. Solving arbitrary shaped fins analytically is highly impractical. So to avoid this they could be analyzed using computational fluid dynamics. Finite volume method is most efficient than FDM and FEM.The simulation process continues till the solution gets converged.

Computational Fluid Dynamics involves three steps.

1) Preprocessing

2) Solver

3)Post processing

The accuracy of the solution depends on many parameters like element quality, Jacobean, warpage, skewness etc. To get good accuracy of solution we need to maintain good element quality and see that curvatures are captured to maximum possible extent. Specifying the boundary conditions correctly is very important. In the cases of fins, the velocity related boundary conditions are important to specify at inlet. Outlet can be any pressure-based boundary condition. It is also important to import fluid properties correctly. Here for the case of fins, temperature boundary condition should be given. Selection of material for the fin also plays a crucial role. The heat transfer analysis is done in FLUENT module in ANSYS. The analysis is performed keeping in mind that the vehicle is moving at an average speed of $60 \mathrm{kmph}$. The good meshing quality is obtained (i.e. minimum element quality is 0.4 ). The equation of continuity, momentumequation and energy equations are solved. Energy equation is turned on and flow is idealized to laminar. Convergence occurred at 32 to 40 iterations for all the fins considered. . Large enclosures are created to capture the maximum possible heat dissipation rate. Then Boolean operation is performed so that the fin curvatures are captured. Curvature and proximity based meshing process is selected to ensure good mesh. The solution is initialized by computing inlet velocity. And also mesh check is performed before running solution. Simple scheme is used to solve.

\section{MESHING AND BOUNDARY CONDITIONS}

Meshing process is very important in simulation as finite volume method is concerned and the accuracy depends on the maximum number of elements as one of the parameter. All the fins triangular, square, elliptical and triangular notch with elliptical hole which are meshed with hexahedral elements in this research work as these elements are stiffer than hex mesh elements and the building of mesh was easier than that of hexahedral mesh. This was done by sizing edge method. During the meshing process the number of elements for triangular, square, elliptical and triangular with elliptical notch was found 1,57,073,12,26,876, 5,07,654 and 4,80,090 respectively.

Published By:

Blue Eyes Intelligence Engineering

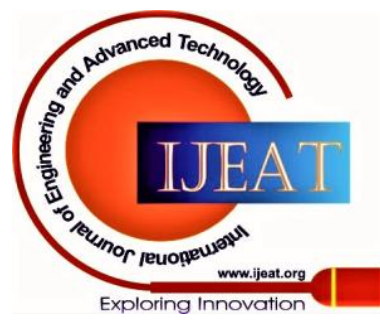


The boundary conditions at the inlet was considered as1) velocity at the inlet 60 kilometers per hour 2) Temperature at the inlet was 80 degrees Celsius.

\section{MESHING OF THE FINS}

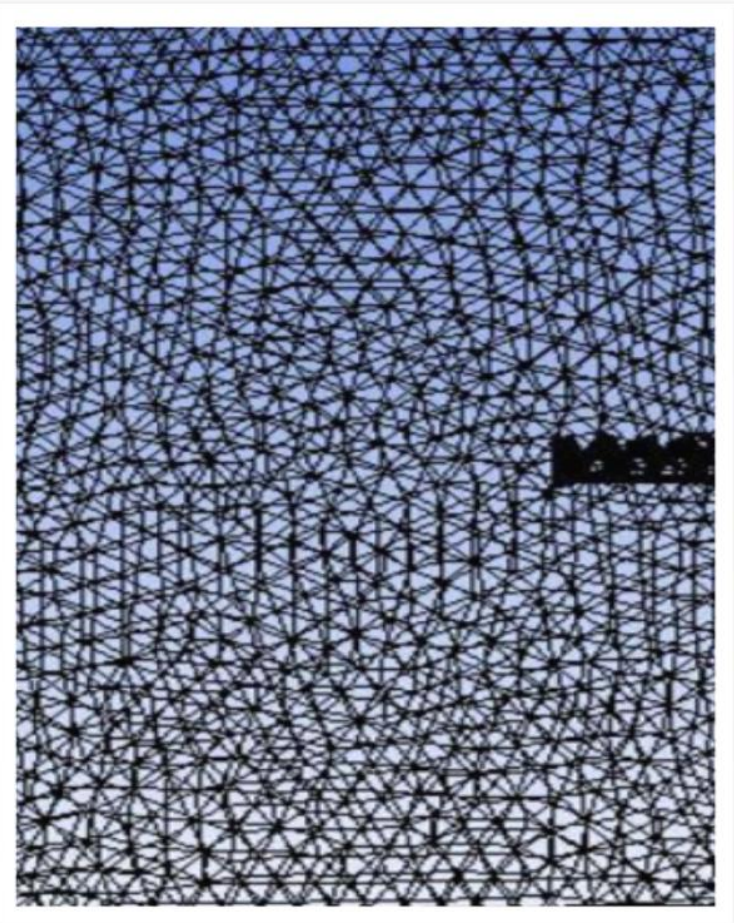

Fig.5 Meshed Triangular notch

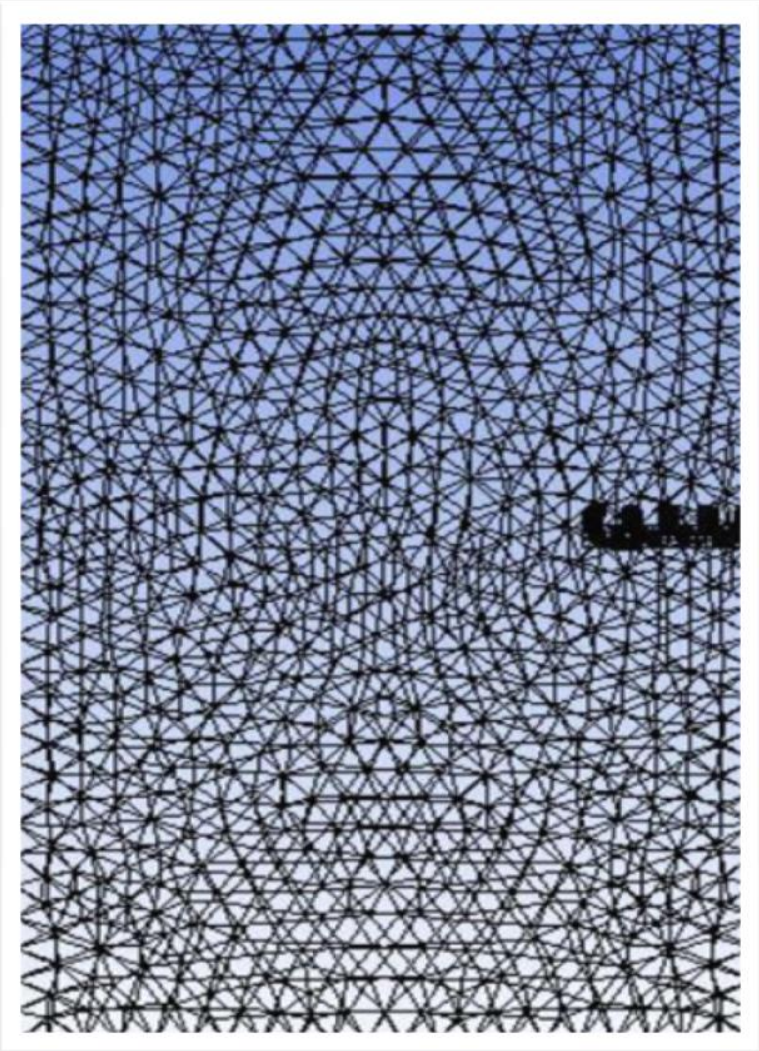

Fig.6 Meshed Squared notch

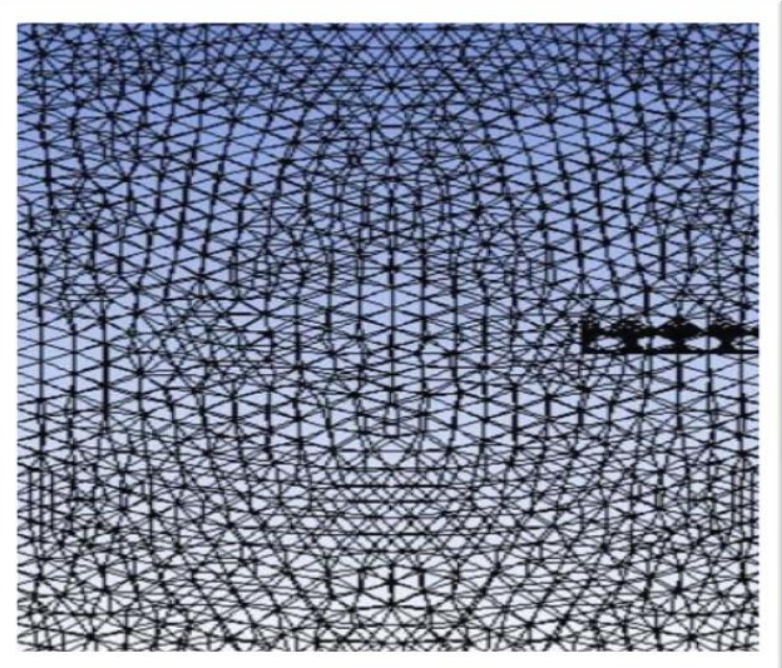

Fig.7 Meshed Triangular notch elliptical hole

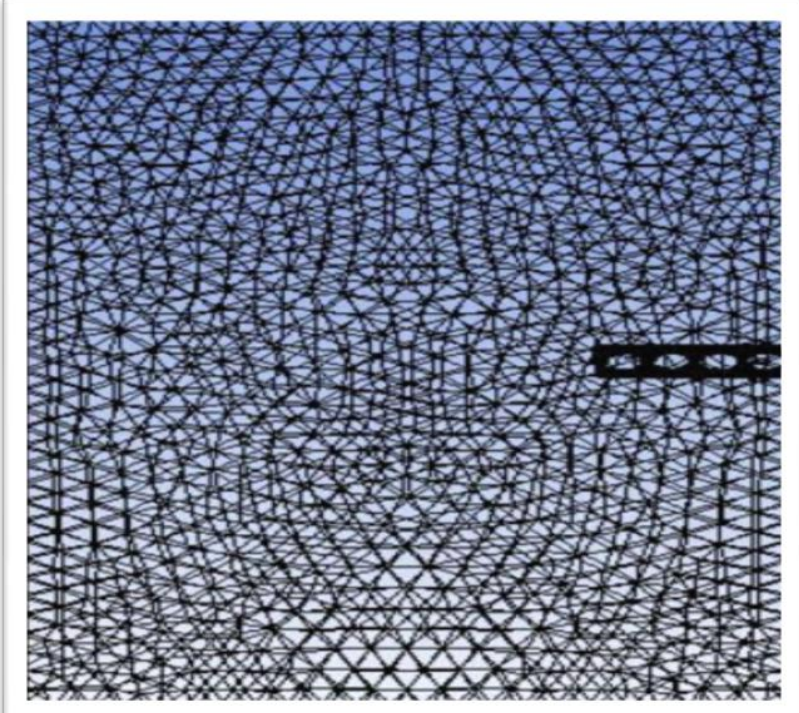

Fig.8 Meshed Elliptical hole

VIII. HEAT TRANSFER RATE

The heat transfer rate through each fin is shown below,

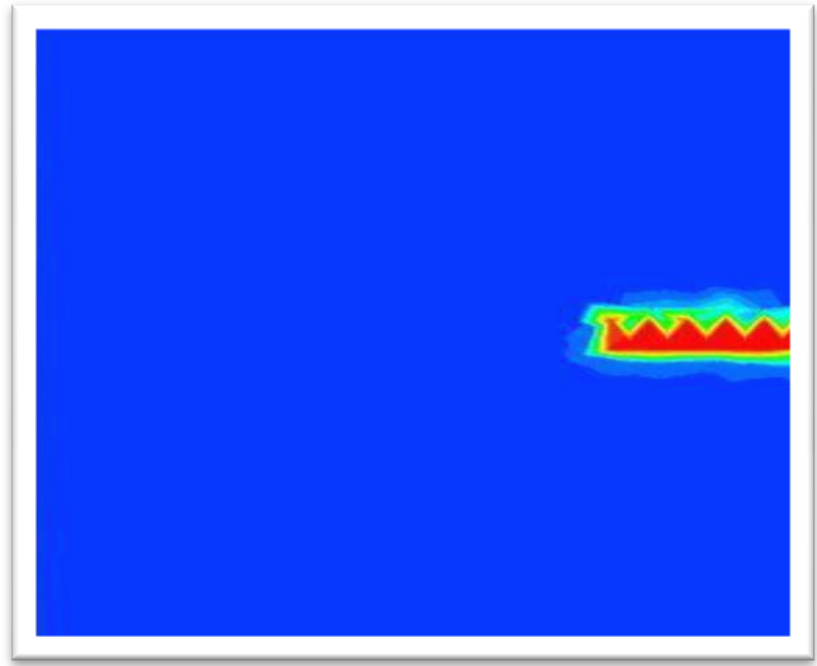

Fig.9 Triangular notch

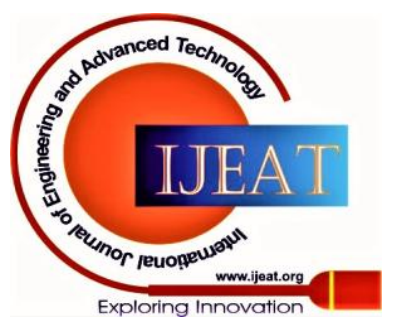

Blue Eyes Intelligence Engineering 


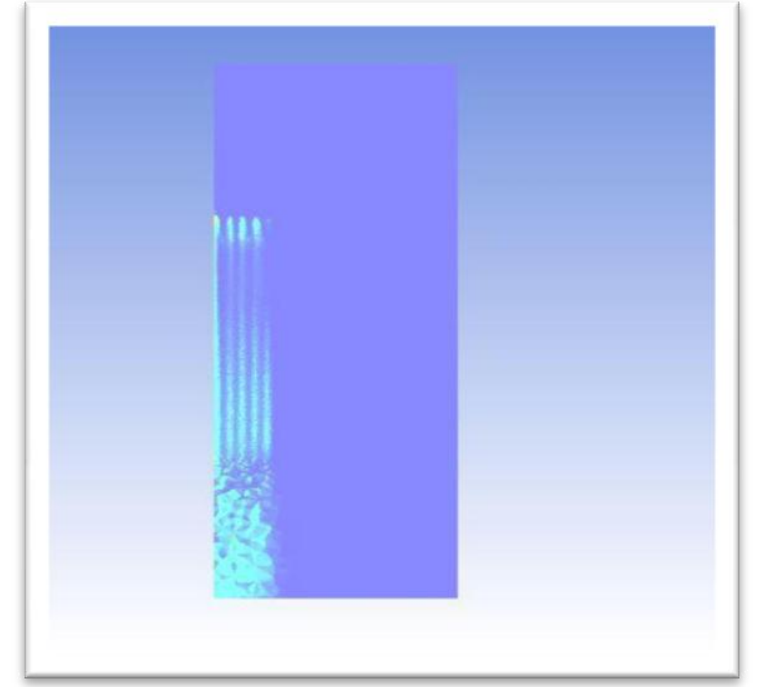

Fig.10 Squared notch

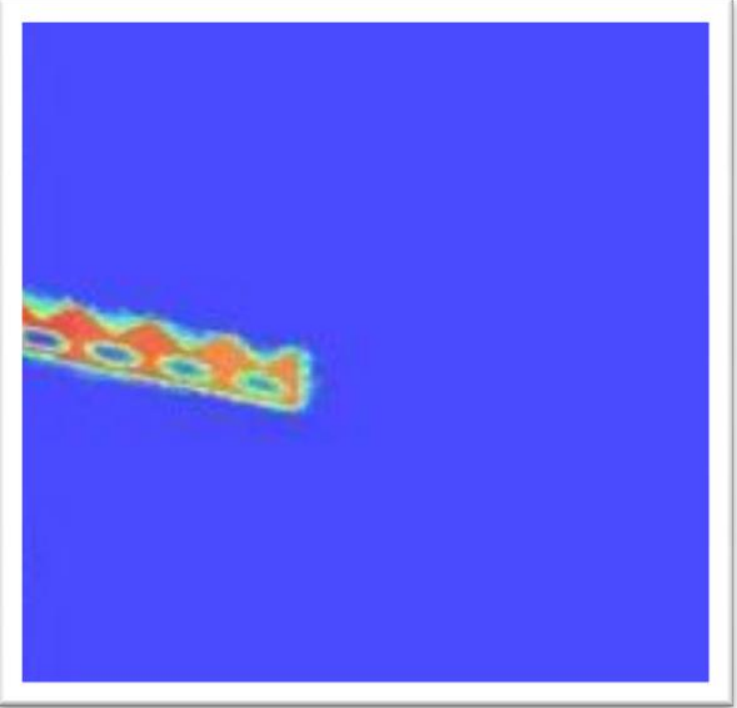

Fig.11 Triangular notch elliptical hole

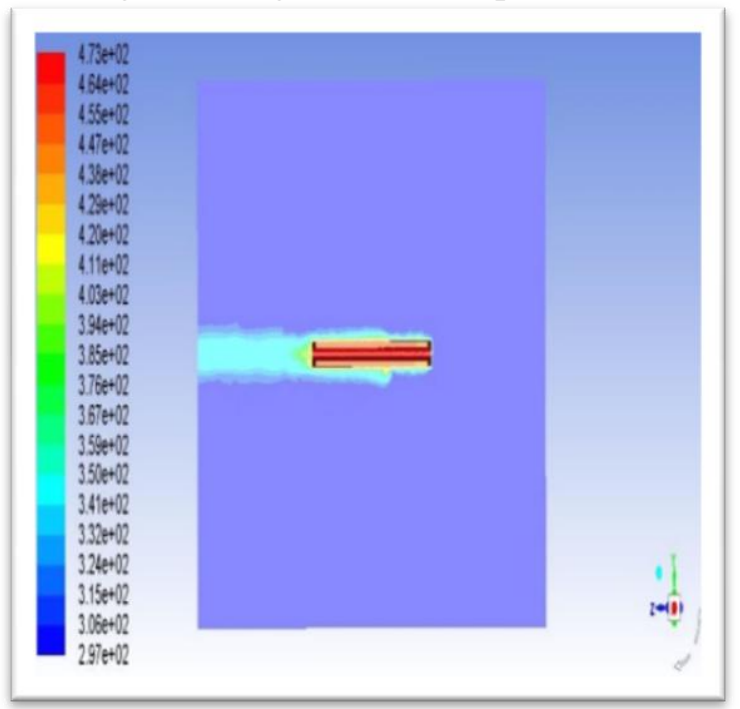

Fig.12 Elliptical hole

\section{RESULTS AND ANALYSIS}

- The heat transfer rate for triangular notch was found 104 watt.

- The heat transfer rate for square notch was found 109 watt.

- The heat transfer rate for triangular notch with elliptical hole was found 114watt.

- The heat transfer rate for elliptical hole notch was found 116 watt.

. The results from CFD analysis shows that fin with elliptical hole has greater heat transfer rate than other models of fins used in the analysis. As the heat dissipation rate is more for elliptical hole, we can conclude that the fin with elliptical hole is the efficient fin to transfer heat. As compared to fins of regular shape arbitrary shaped fins are giving better heat transfer rate as the surface area of all the fins were taken same.

\section{REFERENCES}

1. "AkshendraSoni”, Study of Thermal Performance between Plate-fin, Pin-fin and Elliptical Fin Heat Sinks in Closed Enclosure under Natural Convection, International Advanced Research Journal in Science, Engineering and Technology, Vol. 3, Issue 11, November 2016.

2. "K. Sathishkumar, K.Vignesh, N.Ugesh, P.B.Sanjeevaprasath, S.Balamurugan", Computational Analysis of Heat Transfer through Fins with Different Types of Notches, Vol-4, Issue-2, Feb- 2017.

3. "N.Nagarani", Experimental Heat Transfer analysis On Annular Circular and Elliptical Fins, International Journal of Engineering Science and Technology, Vol. 2(7), 2010, 2839-2845.

4. "Mayank Jain, MahendraSankhala, Kanhaiya

5. Patidar, Lokesh Aurangabadkar", Heat Transfer Analysis And Optimization Of Fins By Variation In Geometry,Volume- 5, Issue-7, Jul.-2017.

6. "Pravin Kamble, S.N Doijode , Geeta Lathkar", A Review on Experimental Study of Heat Transfer from Plate Fin in Mixed Convection Mode, Volume 4 Issue 7, July 2015.

7. "N.A.Nawale, A.S.Pawar", Experiment On Heat Transfer Through Fins Having Different Notches, IOSR Journal of Mechanical and Civil Engineering 2278-1684,p-ISSN: 2320-334X,

8. PP 46-49

9. “A.-R. A. Khaled", Investigation of Heat Transfer Enhancement Through Permeable Fins,Journal of Heat Transfer 132(3),Volume 132, Issue 3,March 2010.

10. "VKarthikeyan, R. Suresh Babu, G. Vignesh Kumar", Design and Analysis of Natural Convective Heat Transfer Coefficient Comparison between Rectangular Fin Arrays with Perforated and Fin Arrays with Extension, International Journal of Science, Engineering and Technology Research (IJSETR), Volume 4, Issue 2, February 2015.

11. "Sunil S, Gowreesh S S, Veeresh B R", Heat Transfer Enhancement and Thermal Performance of Extended Fins,International Journal of Engineering and Advanced Technology (IJEAT)ISSN: 2249 - 8958, Volume-5, Issue-5, June 2016.

12. "Sanjay Kumar Sharmal and Vikas Sharma",Maximising The Heat Transfer Through Fins Using Cfd As A Tool, International Journal of Recent advances in Mechanical Engineering (IJMECH) Vol.2, No.3, Aug2013.

\section{AUTHORS PROFILE}

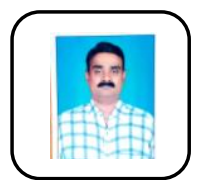

K.Balashowry Professor, department of Mechanica Engineering having 28 years of Teaching and 15 years of Research Experience in the area of computation fluid dynamics. Using Computational Fluid Dynamics split injection research work has been attempted, wherein simultaneous reduction of $\mathrm{NO}$ and Soot have been reduced to a great extent. The same simulated work has been validated with the experimental work by modifying the shaft and the values which obtained by experiments are within five percent range. Published nearly 25 Journal papers in national and international journals. Member of MISTE, LMC, IAENG, IRED. Area of interest is working with Diesel Engines using computational fluid dynamics

Published By:

Blue Eyes Intelligence Engineering

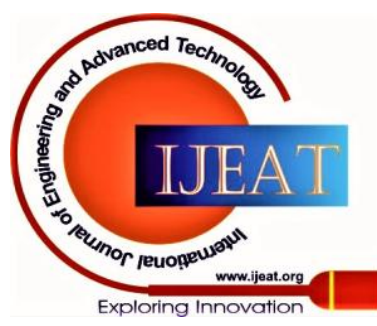


T. Sai Krishna, 3rd year student pursuing my bachelor degree from VNRVJIET.I am a member of American Society for Mechanical Engineers and my membership ID is 103171565. I have attended ASTRO ENGINEERING workshop and participated in technical events conducted during my college technical fest. Attended a seminar on Artificial Intelligence in Mechanical Engineering. I am good at Auto Cad, Solidworks and beginner in ANSYS. Being an Astrophysics enthusiast, I regularly attend lectures by LIGO scientists. I read books related to Astronomy like COSMOS by Carl Sagan. In addition to these I also do programing in $\mathrm{C}$ and Python.

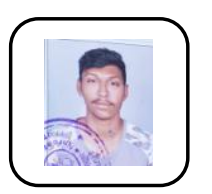

K. Sai Hari Charan Reddy from VNR VJIET college pursuing 4th year of mechanical engineering. I am a member of SAE INDIA and my membership id is 7180433168. I am a former team member of BAJA team in my college. I have done a solar electric vehicle, ALL TERRAIN vehicle and UAV in my preceding years of Btech. I am also a social service provider and former member of NSS. I have attended competitions like ELECTRIC SOLAR VEHICLE CHAMPIONSHIP, SAE BAJA and SAE AERO DESIGN CHALLENGE. have attended seminars conducted by TEDX and also participated in technical fests in my college. I am good at ANSYS, hyper mesh, Catia, Solidworks and MATLAB. I do read books like quantum field theory, standard model, etc. I am a physics enthusiast.

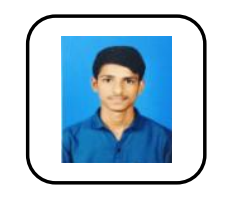

Mandhula Kalyan. Iam from VNR VJIET engineering college studying in mechanical branch. I have participated in some events like engine assembling and disassembling workshop as a part of our college fest. I am also a member of team that made a electric solar vehicle in design department and participated in Electrical Solar Vehicle Championship ESVC and I have attended in Machine Learning and AI workshop which was held at IIT Hyderabad. I am good at Auto Cad and basics of Catia. I am very much interested in interior parts of the engine and automobiles. I also know programming languages like $\mathrm{C}, \mathrm{C}++$, Python.

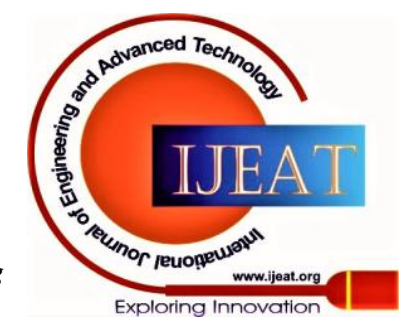

